\title{
IL-36 in chronic inflammation and fibrosis - bridging the gap?
}

\author{
Michael Elias, ${ }^{1,2}$ Shuai Zhao, ${ }^{1,2}$ Hongnga T. Le, ${ }^{1,2}$ Jie Wang, ${ }^{1,2,3}$ Markus F. Neurath, ${ }^{4}$ Clemens Neufert, ${ }^{4}$ Claudio Fiocchi, ${ }^{1,2}$ \\ and Florian Rieder ${ }^{1,2}$
}

'Department of Inflammation and Immunity, Lerner Research Institute, Cleveland Clinic, Cleveland, Ohio, USA. ²Department of Gastroenterology, Hepatology and Nutrition, Digestive Diseases and Surgery Institute, Cleveland Clinic, Cleveland, Ohio, USA. ${ }^{3}$ Henan Key Laboratory of Immunology and Targeted Drug, Xinxiang Medical University, Xinxiang, Henan Province, China. ${ }^{4}$ Department of Medicine 1 and Deutsches Zentrum Immuntherapie DZI, Universitaetsklinikum Erlangen, University of Erlangen-Nürnberg, Erlangen, Germany.

\begin{abstract}
IL-36 is a member of the IL-1 superfamily and consists of three agonists and one receptor antagonist (IL-36Ra). The three endogenous agonists, IL-36 $\alpha,-\beta$, and $-\gamma$, act primarily as proinflammatory cytokines, and their signaling through the IL-36 receptor (IL-36R) promotes immune cell infiltration and secretion of inflammatory and chemotactic molecules. However, IL-36 signaling also fosters secretion of profibrotic soluble mediators, suggesting a role in fibrotic disorders. IL-36 isoforms and IL-36 have been implicated in inflammatory diseases including psoriasis, arthritis, inflammatory bowel diseases, and allergic rhinitis. Moreover, IL-36 has been connected to fibrotic disorders affecting the kidney, lung, and intestines. This review summarizes the expression, cellular source, and function of IL-36 in inflammation and fibrosis in various organs, and proposes that IL-36 modulation may prove valuable in preventing or treating inflammatory and fibrotic diseases and may reveal a mechanistic link between inflammation and fibrosis.
\end{abstract}

\section{Introduction}

First identified in 1988 as a member of the IL-1 superfamily, interleukin-36 (IL-36) plays a role in the initiation and progression of inflammatory and fibrotic diseases (1-7). In fact, current evidence suggests that IL-36 may serve as a bridge between inflammation and fibrosis $(4,7,8)$. Herein, we review the basic biology of IL-36 in health and diseases, with a special emphasis on tissue remodeling. We also highlight recent discoveries in the role of IL-36 in tissue fibrosis, and we provide a rationale for the use of IL-36-targeted therapies in inflam fatory and fibrotic conditions.

\section{Methods}

Relevant literature from 1988 to 2020 was searched in EMBASE, MEDLINE, and the Cochrane library, and supplemented by manual review of selected references from original and review articles meeting the search criteria established by ME, SZ, and FR.

\section{Authorship note: ME and SZ contributed equally to this work.}

Conflict of interest: FR is a consultant to Agomab, Allergan, AbbVie, Boehringer Ingelheim, Celgene, DISC, Cowen, Falk Pharma, Genentech, Gilead, Gossamer, Guidepoint, Helmsley, Index Pharma, Jannsen, Koutif, Metacrine, Morphic, Origo, Pfizer, Pliant, Prometheus, Receptos, RedX, Roche, Samsung, Takeda, Techlab, Theravance, Thetis, and UCB, and received funding from the NIH, Helmsley Charitable Trust, Crohn's and Colitis Foundation, Rainin Foundation, UCB, Boehringer Ingelheim, Pliant, Morphic, and BMS. MFN is an advisor for Abbvie, Boehringer, Janssen, PPM, Takeda, Janssen, Roche, and Pentax. CF received speaker fees from UCB, Sandoz, and Janssen, and is a consultant for Athos Therapeutics. CN served as advisor to, or received speaker fees from, Boehringer Ingelheim, BMS, Chugai, Roche, Servier, Abbvie, and Merck Sharp \& Dohme.

Copyright: () 2021, American Society for Clinical Investigation.

Reference information: J Clin Invest. 2021;131(2):e144336.

https://doi.org/10.1172/JCl144336.

\section{Biology of IL-36}

IL-36 belongs to the IL-1 superfamily and consists of four iso-

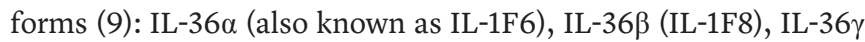
(IL-1F9), and IL-36 receptor (IL-36R) antagonist (IL-36Ra or IL-1F5). IL-36 $\alpha,-\beta$, and $-\gamma$ are proinflammatory agonists and trigger IL-36R signaling, while IL-36Ra inhibits IL-36R signaling $(3,9,10)$. Binding of each agonist to IL-36R leads to recruitment of the IL-1 receptor accessory protein IL-1R3 (IL-1RAcP) and drives signaling via myeloid differentiation primary response 88 (MyD88), MAPK, and NF- $\mathrm{B}$ (11-13). IL-36Ra binding, conversely, fails to recruit IL-1RAcP and does not initiate a signaling response, acting as a true IL-36 antagonist (14).

Distribution and cellular source. IL-36 isoforms have been found in multiple tissues, including synovial, cardiac, neural, and lymphatic tissues, and are expressed by a broad variety of cell types such as keratinocytes, lymphocytes, monocytes, myeloid dendritic cells (DCs), monocyte-derived DCs, plasmacytoid DCs, and plasma cells (2, 15-19). IL-36 isoforms induce distinct gene expression (Table 1) and functional changes (Figure 1) in different cell types, and specific IL-36 isoforms are induced in a cell type-selective manner by different stimuli (Table 2). This indicates that IL-36 isoforms are widely expressed in human tissues and can be induced by IL-36 itself, but also by other cytokines, chemokines, and growth factors present in inflammation and fibrotic diseases. Of note, IL-36 is highly expressed in epidermal, bronchial, gingival, and intestinal epithelial layers and can be upregulated upon contact with bacterial components, suggesting a relevant function at barrier interfaces $(12,20)$. Examples for IL-36 and its relevance in tissue remodeling as well as its relevance in inflammation include IL-36 $\alpha$ being expressed in pancreatic myofibroblasts (8), abundant IL-36 $\gamma$ being produced by colonic myofibroblasts in response to IL-1 $\beta$ and TNF- $\alpha$ (21), and IL-36 activating intestinal epithelial cells 
Table 1. Gene expression by different cell types in response to IL-36 isoform stimulation

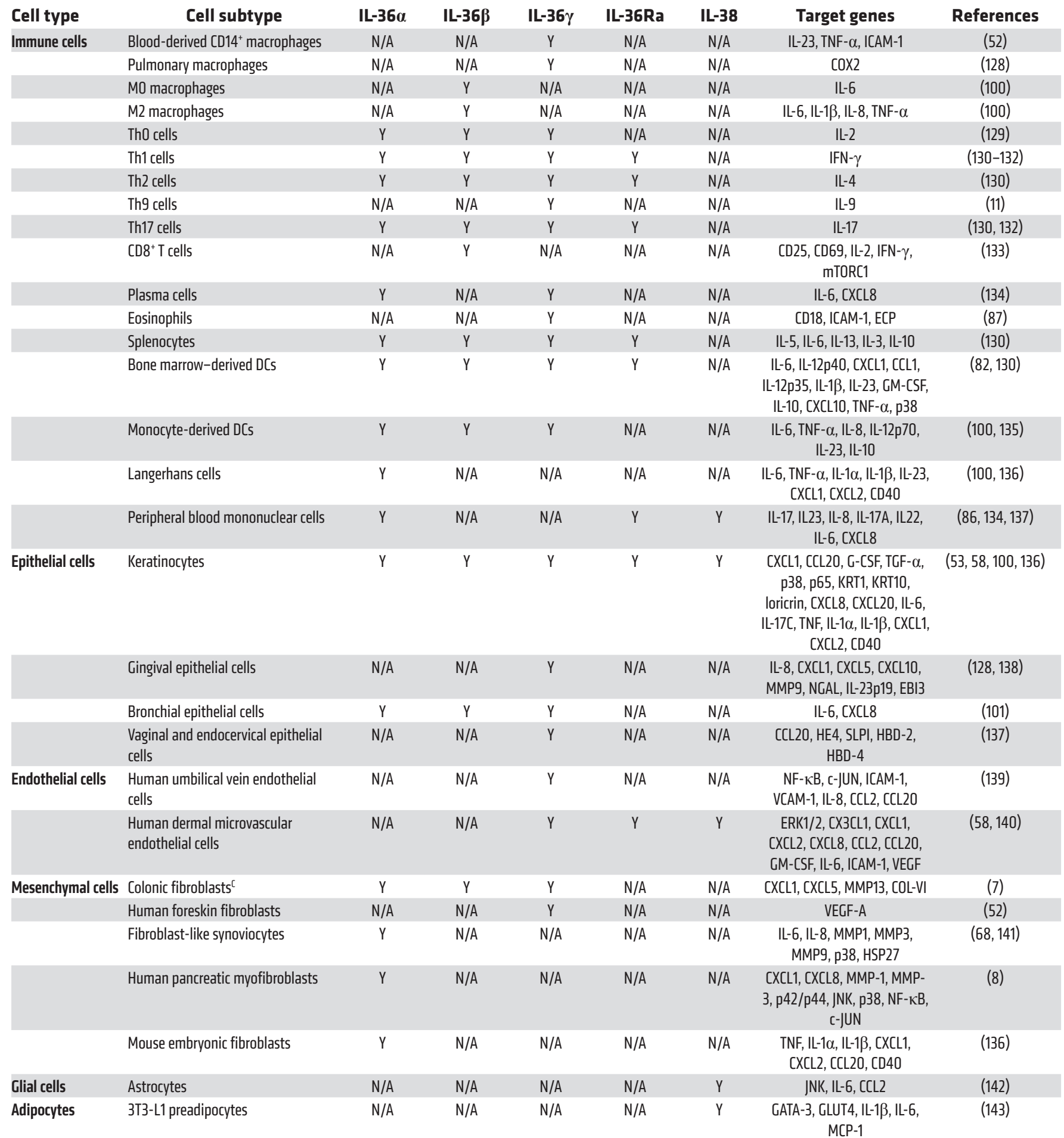

ECP, eosinophil cationic protein; p38, p38 mitogen-activated protein kinases; p65, NF-кB transcription complex; KRT, keratin, type II cytoskeletal; NCAL, neutrophil gelatinase-associated lipocalin; EBI3, Epstein-Barr virus-induced 3; HE4, human epididymis protein 4; SLPI, secretory leukocyte protease inhibitor; HBD, human $\beta$-defensin; GLUT4, glucose transporter type 4. ${ }^{A} \mathrm{~N} / \mathrm{A}$ indicates not yet reported. ${ }^{\mathrm{B} Y}$ indicates cell activation. $\mathrm{CL}-36 \alpha,-\beta$, and $-\gamma$ cocktail used and IL-36 isoform was not specified. 


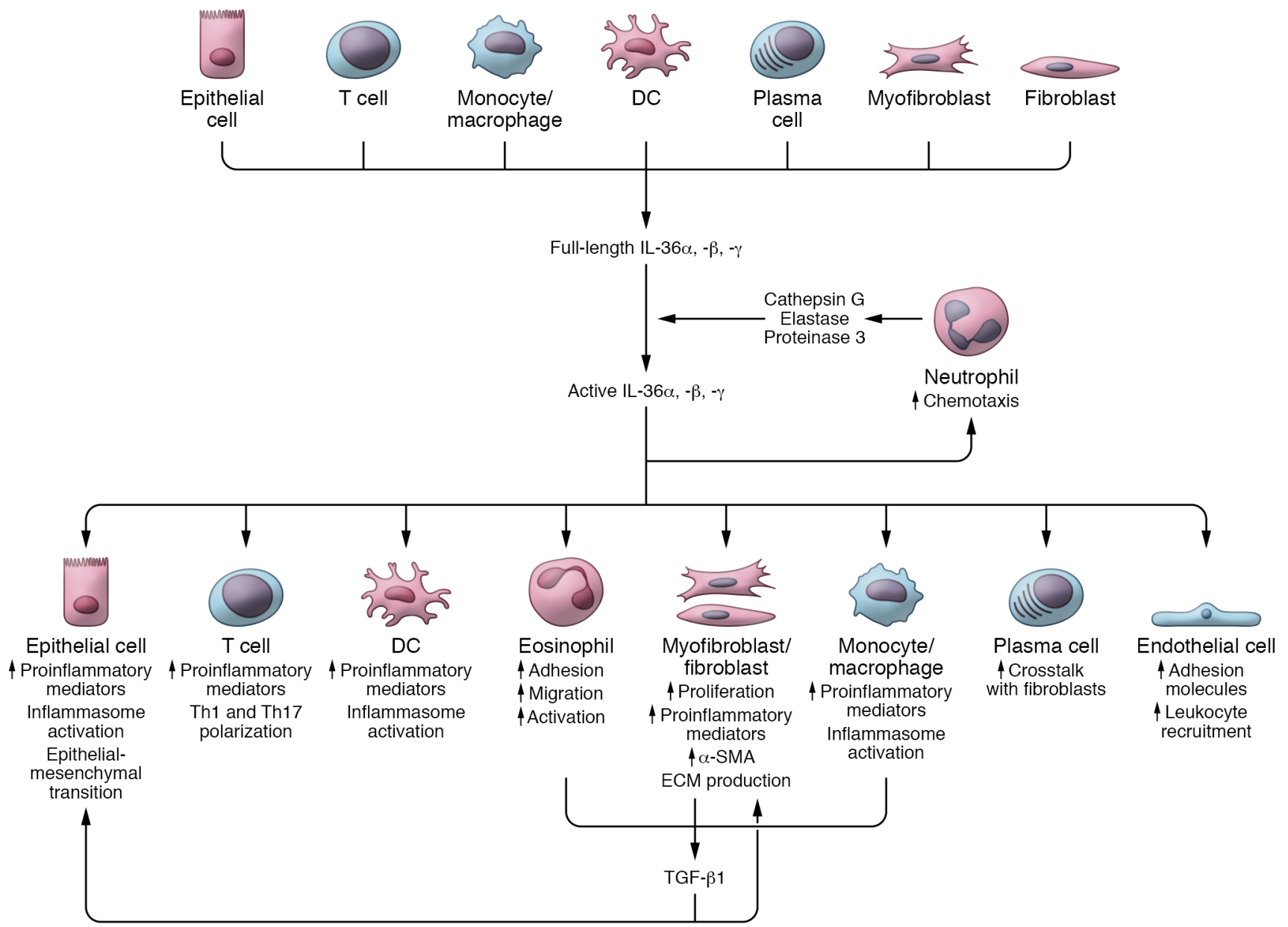

Figure 1. Cellular sources of IL-36 and function of IL-36 in distinct cell types. TGF- $\beta$, transforming growth factor $\beta$.

and fibroblasts (22). IL-36 isoforms can be differentially regulated in the same tissue. For instance, a study on early pregnancy reported a decrease in IL-36 $\alpha$ and $-\beta$ in uterine luminal and glandular epithelia, but an increase in IL-36 $\gamma$, which can exert specific functions (10). The expression of IL-36 at barrier interfaces and its variations in the expression of isoforms in remodeling organs are all compatible with an important role for IL-36 in healing processes at diverse sites. In support of the importance of IL-36 and the concept of its diverse cellular sources and broad factors inducing its expression, IL-36 isoforms are present in essentially all healthy human tissues and organs (Table 3).

Processing. IL-36 exerts low biological activity in its full-length precursor form, requiring proteolytic posttranslational processing to become fully active (23), and N-terminal truncation of IL-36 $\alpha,-\beta$, and $-\gamma$ increases their biological activity by amplifying binding affinity for IL-36R $(23,24)$ (Figure 1). Still, unprocessed IL-36 $\alpha$ can regulate experimental murine psoriasis via a self-amplifying inflammatory loop with IL-1 $\alpha$ (25), indicating that IL-36 $\alpha$ can display activity without being fully processed. Unlike other IL-1 family members, IL-36 members do not exhibit caspase- 1 cleavage sites required for the subsequent secretory processes, suggesting that variable mechanisms can mediate secretion (26-28). Neutrophil granule-derived serine proteases, including cathepsin $\mathrm{G}$, elastase, and proteinase 3 , are major proteolytic activators of IL-36 $\alpha,-\beta,-\gamma$, and IL-36Ra (27). In psoriatic human skin, both cathepsin $G$ and elastase are capable of activating IL-36 $\alpha$, while
IL-36 $\beta$ can be activated by cathepsin G-like activity, and IL-36 $\gamma$ can be activated by elastase (26). Interestingly, IL-36 can promote neutrophil infiltration in psoriasis and chronic rhinosinusitis $(17,29)$, inducing a positive feedforward loop that promotes its own activation through neutrophil attraction. Cathepsin S, a cysteine protease expressed by antigen-presenting cells (APCs), such as DCs (30), and epithelial cells (31), cleaves and activates IL-36 $\gamma$ in skin cells, reinforcing the notion of IL-36 action at barrier surfaces (31). Finally, keratinocyte IL-36 $\gamma$ expression has been found to be dependent on caspase-3/7-directed cleavage (32), and neutrophil elastase can cleave IL-36Ra into its active antagonistic form in blood leukocytes and skin cells (33). Combined, these results indicate that a variety of neutrophil-, APC-, and epithelial cell-derived enzymes can activate all four IL-36 isoforms, but their processing appears to be context dependent and dysregulated in disease states (26). This activation not only provides an amplifying signal in inflammation, but also feeds a self-perpetuating loop of IL-36 activation leading to immune and nonimmune cell activation and recruitment driving additional IL-36 production and cleavage. Of relevance to therapies, proteases are targetable; rather than blocking IL-36 itself, inhibiting its cleavage is a reasonable proposition.

Signaling. IL-36R is a heterodimeric complex composed of the subunit IL-1R-related protein 2 (IL-1Rrp2) and a co-receptor subunit, IL-1RAcP (12). Binding of IL-36 agonists to IL-36R triggers intracellular signaling (34). IL-36R contains an extracellular 
Table 2. Expression of the IL-36 receptor, stimuli that induce IL-36 isoforms, and type of IL-36 isoforms produced

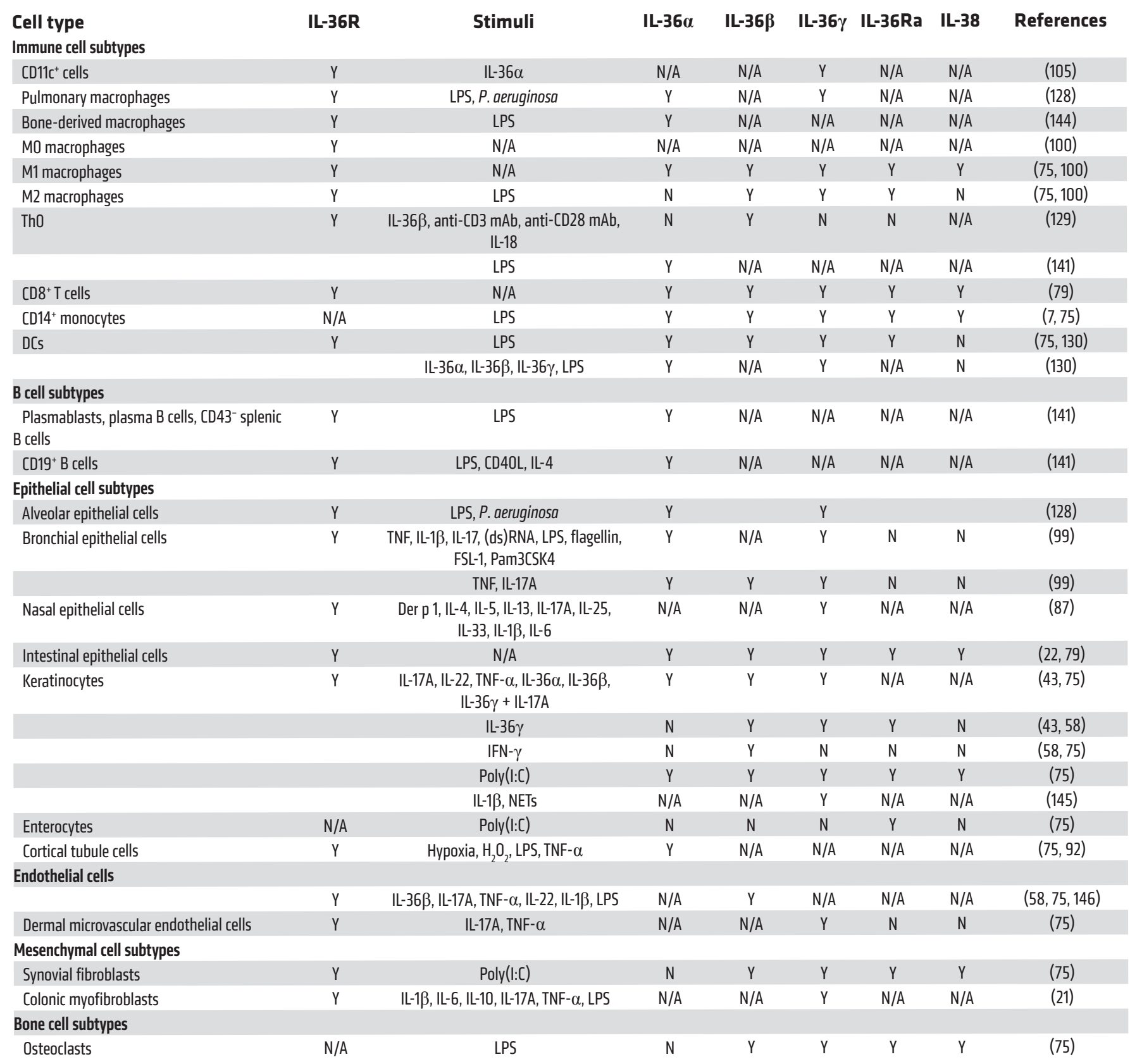

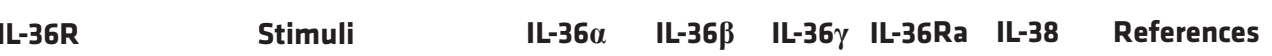

Immune cell subtypes

P. aeruginosa, Pseudomonas aeruginosa; Der p 1, Dermatophagoides pteronyssinus group 1; (ds)RNA, double-stranded RNA; FSL-1, fibroblast-stimulating lipopeptide-1; NETs; neutrophil extracellular traps. ${ }^{A} \mathrm{~N} / \mathrm{A}$ indicates not yet reported. ${ }^{\mathrm{B}} \mathrm{N}$ indicates the type of IL-36 isoform not produced. ${ }^{\mathrm{C}} \mathrm{Y}$ indicates the type of IL-36 isoform produced.

domain that binds its agonists and an intracellular Toll/IL-1 receptor (TIR) domain that is linked to the TIR domain on IL-1RAcP, leading to activation of signaling via formation of a MyD88/IL-1 receptor-associated kinase 1 (IRAK1)/IRAK2 signaling platform (12) (Figure 2). Of note, the single-nucleotide polymorphism (SNP) A471T in the TIR domain dampens its interaction with IL-1RAcP and downregulates signal transduction (13). IL-36Ra mediates its antagonistic effect by binding IL-36R and inhibiting the recruitment of IL-1RAcP and the dimerization of the IL-36R/IL-1RAcP complex $(23,35)$. IL-38, another IL-1 family member, can also bind to IL-36R and act as an antagonist (36).

The proinflammatory activity of IL-36 is strictly dependent on MyD88. IL-36R/MyD88 signaling in T cells promotes skin inflammation upon Staphylococcus aureus exposure by producing IL-17A/F (37), and MyD88 knockdown affects intracellular signaling of both IL-36 $\alpha$ and $-\gamma$ and suppresses production of IL-6, CXCL1, CXCL2, and CXCL8 in colonic myofibroblasts (38). A gene expression sequencing study compared normal to MyD88-deleted keratinocytes and con- 
A

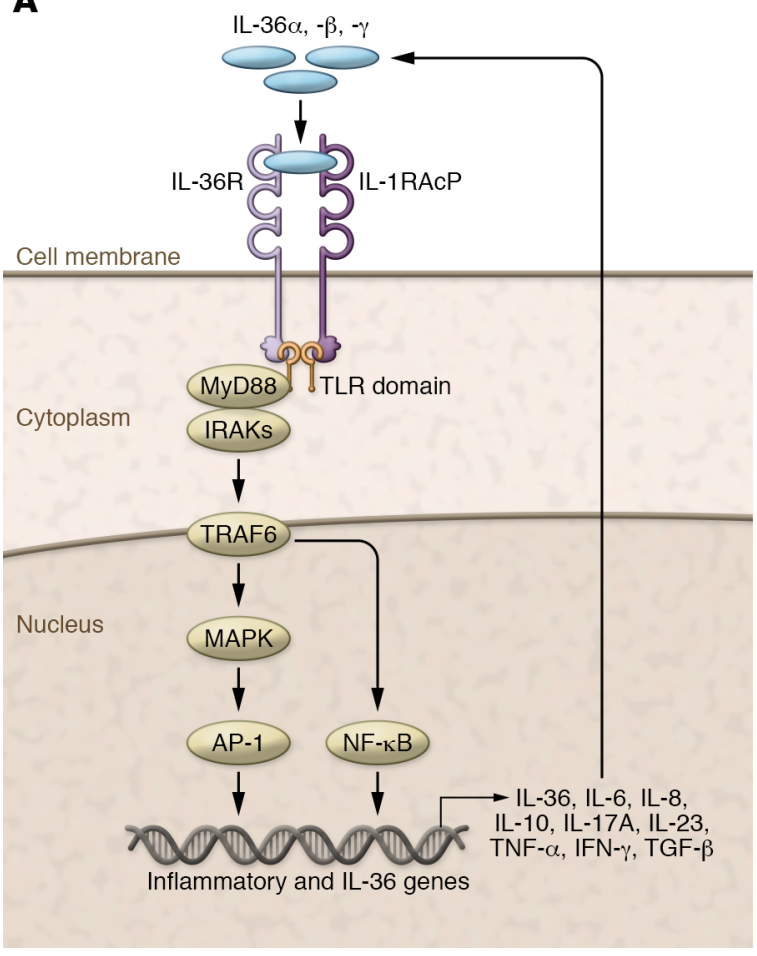

B

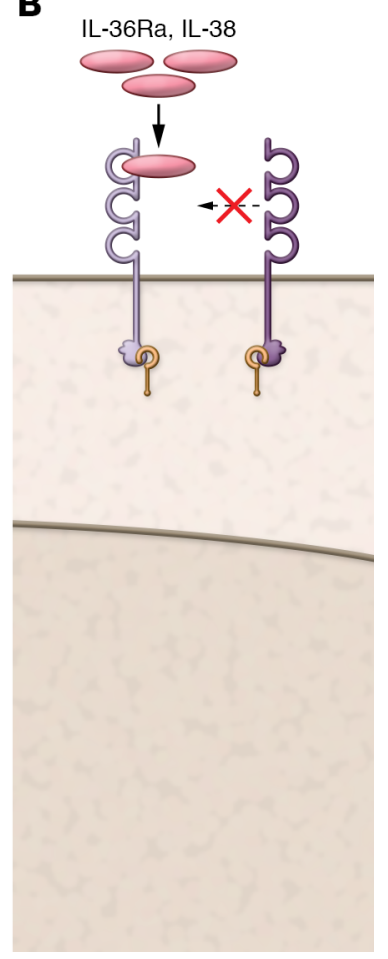

Figure 2. Inflammatory pathways of IL-36 and IL-36R. (A) IL-36 agonists stimulate inflammatory and epithelial cells, activating the NF-KB pathway, leading to the production and secretion of inflammatory cytokines creating a feedback loop. (B) IL-36 antagonists inhibit the binding of the IL-36 co-receptor, truncating the signaling pathway. IL-1RAcP, IL-1 receptor accessory protein IL-1R3; MyD88, myeloid differentiation primary response 88; AP-1, activator protein 1; IRAKs, interleukin-1 receptor-associated kinases.

firmed that IL-36 responses are entirely dependent on MyD88 (39). The N-terminal death domain of MyD88 is important for recruitment of IRAK1-IRAK2 or IRAK2-IRAK4 complexes (40, 41), forming a multiprotein complex that recruits TNF receptor-associated factor 6 and activating the MAPK signaling pathway (12). This, in turn, leads to the activation and nuclear translocation of NF-KB and activator protein 1 (AP-1), which regulate transcription of numerous inflammatory genes $(12,42)$ (Table 1 and Figure 2). For instance, IL-36 induces production of TNF- $\alpha$, IL-6, and IL-8 in keratinocytes that involves a feedback loop between the IL-36 and Th17 cytokines in psoriatic tissues (43). IL-36 $\alpha$ and $-\gamma$ have been demonstrated to induce IкB $\zeta$ expression in human keratinocytes (HaCaT cell line) and primary keratinocytes, mediated by NF- $\kappa$ B and STAT3. ІкB $\zeta$ was able to induce upregulation of psoriasis-associated genes mediated by IL-36 $\alpha$ and promote IL-36 $\alpha-$ driven psoriasis-like disease in vivo (44). The same group recently reported that IL-36-mediated IкB $\zeta$ expression was suppressed by abemaciclib (CDK4/6 inhibitor) or CPI-169 (EZH2 inhibitor) in two mouse models of TLR7 agonist imiquimod-mediated or IL-36mediated psoriasis-like skin inflammation (45).

In addition to promoting inflammation via IL-36-dependent activation of MAPK and NF-kB, the relationship between IL-36 and the Wnt signaling pathway has been explored. Through stimulation of autophagy and induction of WNT5A as well as the activation of the COX-2/AKT/mTOR pathway via noncanonical Wnt signaling, IL-36 $\gamma$ confers on monocytes the ability to suppress growth of intracellular Mycobacterium tuberculosis (46). Additionally, inhibitors of Wnt signal-

ing can blunt the IL-36 $\gamma$-driven inflammatory response in $\mathrm{HaCaT}$ cells (47).

\section{IL-36 in inflammatory diseases}

Because of its ubiquitous expression and established role in inflammation, IL-36 is being investigated as a mediator of various clinical conditions and a possible therapeutic target. Table 4 summarizes its involvement in multiple inflammatory diseases.

Psoriasis. Psoriasis represents a mixed autoimmune and autoinflammatory skin disease characterized by hyperproliferation of keratinocytes and infiltration of immune cells (48), and several lines of evidence implicate IL-36 as a central player in its pathogenesis. IL-36 $\alpha$ and $-\gamma$ are upregulated in psoriatic skin at both the mRNA and protein level $(49,50)$, and both IL-17 and IL-22 induce IL-36 production in human keratinocyte cultures, while neutralization of IL-22 downregulates all three IL-36 agonists in normal and psoriasislike mouse skin. Moreover, all IL-36 agonists were found to synergize with IL-17 and TNF- $\alpha$ in primary human keratinocytes as well as murine models of psoriasis, increasing their own expression and stimulating production of proinflammatory cytokines TNF- $\alpha$, IL-6, and IL-8 (43). Additionally, IL-36 induces and regulates the expression and function of Th17 cytokines through activation of Th17 cells (43). IL-36y stimulates IL-23, another driver of psoriasis, in macrophages of psoriatic patients $(51,52)$. The importance of the IL-36R is also highlighted in experimental models; IL-36R-knockout mice are protected from imiquimod-induced skin pathology observed in WT mice, whereas knockouts of IL-36Ra in turn worsen the disease (53). K5.Stat3C mice expressing constitutively activated STAT3 within keratinocytes develop a phenotype resembling psoriasis (54) that can be dramatically attenuated by deleting IL-36R, which is associated with a reduction in IL-23/Th17 expression in skin lesions (55). Finally, intradermal injection of recombinant IL-36 $\alpha$ exacerbates psoriasis by inducing chemokines in human keratinocytes, leading to the recruitment of T cells and APCs (17), which are in turn sources of IL-36, providing another feed-forward loop driving chronic inflammation.

Of the three IL-36 agonists, IL-36 $\gamma$ has garnered recognition as the most robust biomarker for psoriatic skin lesions (56). A gene expression analysis comparing psoriasis to other inflammatory diseases identified IL-36 $\gamma$ as a specific psoriasis marker, a finding confirmed by immunohistochemical staining (57). In the clinic, enhanced IL-36 $\gamma$ serum levels in psoriasis patients closely correlate with worsened clinical disease activity and a decrease in response to anti-TNF- $\alpha$ administration (57). One study suggested that the ratio between serum IL-36 $\gamma$ and IL-38 levels in patients suffering from chronic plaque psoriasis also correlates with disease severity, underscoring the possible therapeutic potential of targeting IL-36/IL-38 in psoriasis (58).

Although numerous agents are available for psoriasis therapy (59), the prominence of IL-36y in disease pathogenesis has made this 


\section{Table 3. IL-36 isoform tissue expression and corresponding cellular sources}

\begin{tabular}{|c|c|c|c|}
\hline Tissue & IL-36 isoform & Cellular source & References \\
\hline Skin & 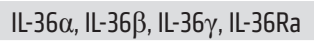 & Keratinocytes, fibroblasts, endothelial cells, macrophages, DCs, Langerhans cells, T cells & $(43,52,147)$ \\
\hline Renal & 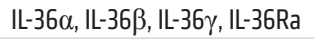 & Epithelial cells, fibroblasts & $(7,91,92,148)$ \\
\hline Brain & 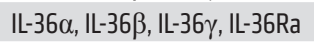 & Glia, microglia, astrocytes & $(149)$ \\
\hline Respiratory tract & 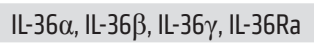 & Epithelial cells, fibroblasts, macrophages & $(3,6,99,107,150,151)$ \\
\hline Intestinal tract & 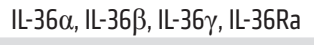 & Fibroblasts, myofibroblasts, epithelial cells, goblet cells, macrophages, glial cells & $(8,10,22,76,152)$ \\
\hline Tonsils & IL-36Ra, IL-36 $\alpha$, IL-36 $\beta$ & Macrophages & $(86,100,153)$ \\
\hline Lymph nodes & IL-36 $\alpha$, IL-36 $\beta$ & T cells & (153) \\
\hline Spleen & IL-36 $\alpha$, IL-36Ra & B cells & $(153)$ \\
\hline Synovium & 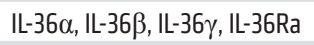 & Monocytes, fibroblasts & $(68,69)$ \\
\hline Heart & IL-36ß, IL-36Ra & N/A & $(153)$ \\
\hline Testis & IL-36 $\beta$ & $\mathrm{N} / \mathrm{A}$ & (153) \\
\hline
\end{tabular}

${ }^{A} \mathrm{~N} / \mathrm{A}$ indicates not yet reported.

isoform a primary therapeutic target. Ambrisentan, an analog of the endothelin receptor A antagonist, was shown to attenuate IL-36yinduced proinflammatory cytokine production in $\mathrm{HaCaT}$ cells and $\mathrm{NIH}-3 \mathrm{~T} 3$ murine fibroblasts (60), and attenuated a psoriatic phenotype in a 3D skin model of human keratinocytes and fibroblasts (60). Spesolimab, a monoclonal antibody against IL-36R, was recently shown to ameliorate generalized pustular psoriasis via inhibition of IL-36 signaling (NCT02978690) (61). The clinical efficacy, duration of effect, and adverse events associated with spesolimab are still under assessment, and a phase II clinical trial is currently ongoing to test its efficacy, safety, and tolerability compared to placebo in patients with moderate to severe pustular psoriasis (NCT03782792). The longterm safety and efficacy of spesolimab in patients with pustular psoriasis that have completed a previous trial (NCTO3135548) are currently being assessed in a phase III trial (NCT03886246).

Arthritis. The most prevalent types of arthritis are psoriatic arthritis (PsA), rheumatoid arthritis (RA), and osteoarthritis (OA) (62). Substantial evidence supports the role of IL-36 in PsA (63). At the genetic level, examination of multiple SNPs in the IL-1 gene family cluster points to IL-36 $\beta$ as a susceptibility locus for PsA (64), and IL-36 $\gamma$ and IL-36Ra gene expression is upregulated in PsA skin (65). At a mechanistic level, Th17 cells are deemed essential in PsA pathogenesis, and Th17 cytokines such as IL-17 and IL-22 contribute to the development of psoriatic plaques and joint erosion $(66,67)$.

Elevated levels of IL-36 $\alpha$ are found in synovial tissue from PsA and RA patients compared with OA patients, and IL-36R and IL-36Ra are consistently expressed in arthritis (68). Additionally, elevated levels of IL-36 $\beta$ were detected in synovial fibroblasts cultured with IL-1 $\beta$ or TNF- $\alpha$ (69). IL-36 $\alpha$ leads to increased IL-6 and IL-8 expression in synovial fibroblasts by activating the $\mathrm{p} 38 / \mathrm{NF}-\kappa \mathrm{B}$ pathway, suggesting a role of IL-36 in synovial remodeling (68). As in PsA, Th17 cells have a role in the progression of RA (70), but in the synovium of human and experimental RA, Th17 cytokines do not correlate with IL-36 expression. This could be explained by a function of IL-36 in RA that is independent of canonical Th17 pathways (67). Interest- ingly, although increased expression of IL-36 $\alpha$ and IL-36R is seen in mice with inflammatory arthritis, IL-36 blockade fails to ameliorate TNF-induced arthritis (71). TGF- $\beta$ signaling has been implicated in the development and progress of OA (72), and the TGFBR2/IL-36 signaling axis was specifically targeted in $\mathrm{Tg} f b r 2^{-/-}$mice, resulting in upregulation of IL-36 $\alpha$ and downregulation of IL-36Ra in the articular cartilage. Intra-articular injection of IL-36Ra attenuated OA progression in $\mathrm{Tg} f \mathrm{fr}^{-/-}$as well as WT mice, suggesting a potential therapeutic effect of IL-36Ra in OA (73). IL-36 agonists have similar expression in the synovium in PsA and RA, but with significantly lower expression of IL-36Ra and IL-38 in PsA compared with that in RA, suggesting distinct regulatory pathways for IL-36 in PsA (73).

Disease-modifying antirheumatic drugs (DMARDs) are routinely used in treatment of RA and PsA (74), and an inadequate response to DMARDs may be linked to an impaired balance between IL-36 agonists and antagonists in PsA synovial tissue (73). To date, there has been no clinical trial evaluating the efficacy of IL-36 blockade in arthritis treatment.

Inflammatory bowel diseases. Inflammatory bowel diseases (IBDs) consist of two major phenotypes - Crohn's disease (CD) and ulcerative colitis (UC). Upregulation of IL-36 $\alpha$ and IL-36 $\gamma$ was observed in inflamed colonic biopsies of patients with active colonic CD compared with unaffected biopsies from the same patients (75). Others reported increased expression of IL-36 $\alpha$ and IL-36 $\gamma$, but not IL-36 $\beta$, in the intestinal mucosa in UC patients $(76,77)$, while a different group found all IL-36 cytokines to be significantly elevated in the colonic mucosa of active UC compared with inactive UC and noninflammatory controls (78). IBD mucosal biopsies reveal a strong expression of IL-36 $\alpha$ mainly in $\mathrm{CD}_{14}{ }^{+}$inflammatory macrophages, while the intestinal epithelium expresses predominantly IL-36 $\gamma$, and IL-36 signaling activates intestinal fibroblasts and epithelial cells (22). In colon samples from IBD patients with fibrostenosis, strong expression of IL-36 $\alpha$ was found to be correlated with the degree of inflammation (7). Recently, the role of the IL-36 antagonist IL-38 was investigated in IBD (79). IL-38-expressing cells were elevated in the serosal, muscular, and submucosal layers 


\section{Table 4. Role of IL-36 isoforms in inflammatory diseases}

\begin{tabular}{|c|c|c|c|c|c|c|}
\hline & IL-36 $\alpha$ & IL-36及 & IL-36 $\gamma$ & IL-36Ra & IL-38 & References \\
\hline Psoriasis & $\begin{array}{l}\text { Induces expression of } \\
\text { IL-1 } \alpha \\
\text { Activation of IL-23/IL-17A } \\
\text { signaling axis }\end{array}$ & $\begin{array}{l}\text { Leads to activation of } \\
\text { IL-23/IL-17A signaling axis } \\
\text { Induces expression } \\
\text { of complement C3, } \\
\beta \text {-defensin-2, S100A9, } \\
\text { TNF- } \alpha\end{array}$ & $\begin{array}{l}\text { Leads to activation of } \\
\text { s IL-23/IL-17A signaling axis } \\
\text { Amplifies TNF- } \alpha \text { and IL-17 } \\
\text { pathways }\end{array}$ & $\begin{array}{l}\text { Exerts protective roles in } \\
\text { cutaneous inflammation } \\
\text { IL36RN mutation disables } \\
\text { its interaction with IL36R } \\
\text { IL-36Ra deficiency drives } \\
\text { skin lesions and induces } \\
\text { IL-23, IL-17, and IL-22 } \\
\text { expression }\end{array}$ & $\begin{array}{l}\text { Suppresses IL-17A } \\
\text { production and restricts } \\
\text { inflammation } \\
\text { Reduces infiltration of } \\
\text { T cells and neutrophils } \\
\text { and reduces production } \\
\text { of psoriasis-related } \\
\text { chemokines involved } \\
\text { in T cell and neutrophil } \\
\text { recruitment and activation }\end{array}$ & $\begin{array}{c}(25,31,49,53,57,58 \\
155-161)\end{array}$ \\
\hline Arthritis & $\begin{array}{l}\text { Induces expression of IL-6 } \\
\text { and IL-8 }\end{array}$ & $\begin{array}{l}\text { Exerts proinflammatory } \\
\text { effects }\end{array}$ & Expressed & $\begin{array}{c}\text { Reduces MMP13 in human } \\
\text { OA chondrocytes }\end{array}$ & Expressed & $(68,69,72,75,162,163)$ \\
\hline IBD & $\begin{array}{l}\text { Induces Th1 cell } \\
\text { differentiation }\end{array}$ & & $\begin{array}{c}\text { Induces Th1 cell } \\
\text { differentiation and } \\
\text { induces TNF- } \alpha \text { expression } \\
\text { in CD keratinocytes } \\
\text { Drives IL-23/IL-22/AMP- } \\
\text { dependent colonic tissue } \\
\text { repair }\end{array}$ & $N / A$ & $\begin{array}{l}\text { Suppresses IL-1 } \beta \text { and } \\
\text { TNF- } \alpha \text { expression }\end{array}$ & $(76,78,82,164)$ \\
\hline Allergic rhinitis & $\begin{array}{l}\text { Promotes Th17 cell } \\
\text { differentiation }\end{array}$ & $\mathrm{N} / \mathrm{A}$ & $\begin{array}{l}\text { Promotes the adhesion, } \\
\text { migration, and activation } \\
\text { of eosinophils }\end{array}$ & $\mathrm{N} / \mathrm{A}$ & $\mathrm{N} / \mathrm{A}$ & $(86,87)$ \\
\hline Lung & $\begin{array}{l}\text { Leads to the recruitment } \\
\text { of Th17 cells and } \\
\text { fibroblast activation } \\
\text { Induces expression of } \\
\text { TNF- } \alpha, \text { CXCL1, CXCL2 }\end{array}$ & $\begin{array}{l}\text { Upregulates the } \\
\text { expression of IL-6 and } \\
\text { CXCL8 in human lung } \\
\text { fibroblasts and bronchial } \\
\text { epithelial cells }\end{array}$ & $\begin{array}{l}\text { Leads to the recruitment } \\
\text { of Th17 cells and } \\
\text { fibroblast activation } \\
\text { Controls neutrophilic } \\
\text { airway inflammation }\end{array}$ & $\mathrm{N} / \mathrm{A}$ & $\mathrm{N} / \mathrm{A}$ & $(99,101,105,108)$ \\
\hline Kidney & $\begin{array}{l}\text { Correlates with acute } \\
\text { kidney injury and leads to } \\
\text { tubular damage }\end{array}$ & $\mathrm{N} / \mathrm{A}$ & $\mathrm{N} / \mathrm{A}$ & $\mathrm{N} / \mathrm{A}$ & $\mathrm{N} / \mathrm{A}$ & $(6,91)$ \\
\hline
\end{tabular}

${ }^{\mathrm{A}} \mathrm{N} / \mathrm{A}$ indicates not yet reported.

of patients with active UC compared with active $\mathrm{CD}$ and noninflamed control subjects, and increased IL-38 gene expression was observed in noninflamed mucosa of UC compared with inflamed UC and controls. Taken together, these results show that IL-38 and IL-36 are increased in the inflamed intestinal mucosa in IBD, with the predominant isoforms being IL-36 $\alpha$ and IL-36 $\gamma$.

An important role of IL-36 in IBD is further supported by several studies performed in models of experimental colitis. In acute dextran sodium sulfate-induced (DSS-induced) colitis, loss of IL-36R signaling leads to an increase in disease activity and reduced survival, suggesting a protective role of IL-36R in this model (22). Accordingly, a different group showed that IL-36 $\mathrm{R}^{-/-}$mice fail to recover from acute DSS-induced colitis and develop a profound reduction in IL-22 (80), which is known to stimulate epithelial proliferation, restitution, and mucosal protection (81). Supporting this, IL-36 $\gamma$-stimulated colonic explants result in increased expression of IL-22 and IL-23 (82) and connect intestinal immune activation to epithelial repair $(83,84)$. Conversely, a different study found that acute DSS-induced colitis was ameliorated in IL-36 $\mathrm{R}^{-/-}$mice and that IL-36R signaling promoted Th1 responses while inhibiting Th17 responses (76). Treatment with the IL-36 antagonist IL-38 attenuates acute DSS-induced colitis in mice and suppresses IL-1 $\beta$ and TNF- $\alpha$ (78). Taken together, these studies in acute DSS colitis models revealed divergent results with pro- as well as antiinflammatory responses of IL-36 signaling. In the chronic models of colitis induced by DSS and 2,4,6-trinitrobenzene sulfonic acid (TNBS), however, IL-36 $\alpha$ mRNA is also elevated, and mucosal inflammation is reduced in IL-36 $\mathrm{R}^{-/-}$mice or by neutralizing anti-IL-36R antibodies (7).

These data triggered a clinical trial on the mechanism of action, clinical effect, safety, and tolerability of spesolimab in patients with UC, which has been completed in an open-label phase II study (NCT03100864), with results being awaited. Another ongoing phase II trial aims to evaluate the safety and efficacy of spesolimab induction therapy in patients with moderate to severe active UC who failed previous biologics therapy (NCT03482635). The long-term safety of spesolimab is under evaluation in a phase II study in patients who have moderate to severely active UC and have completed a previous treatment trial (NCT03648541). Mechanism of action and clinical effect of spesolimab in patients with fistulizing CD have been studied in a phase II trial (NCT03752970), with a readout expected in 2021. Evaluation of the long-term safety and efficacy of spesolimab in patients with perianal fistulizing $\mathrm{CD}$ who had completed previous treatments is currently underway (NCT04362254).

Allergic rhinitis. Allergic rhinitis (AR) is a common inflammatory disorder of the nasal mucosa that is associated with impairments in quality of life, sleep, and work productivity and affects approximately 


\section{Table 5. Role of IL-36 isoforms in fibrotic disorders}

\begin{tabular}{|c|c|c|c|c|c|c|}
\hline & IL-36 $\alpha$ & IL-36ק & IL-36 $\gamma$ & IL-36Ra & IL-38 & References \\
\hline Pulmonary fibrosis & $\begin{array}{l}\text { Induces expression of } \\
\text { inflammatory cytokines } \\
\text { and chemokines and } \\
\text { extracellular matrix } \\
\text { proteins }\end{array}$ & $\begin{array}{l}\text { Induces expression of } \\
\text { inflammatory cytokines } \\
\text { and chemokines and } \\
\text { extracellular matrix } \\
\text { proteins }\end{array}$ & $\begin{array}{l}\text { Induces expression of } \\
\text { inflammatory cytokines } \\
\text { and chemokines and } \\
\text { extracellular matrix } \\
\text { proteins }\end{array}$ & $\mathrm{N} / \mathrm{A}$ & $\begin{array}{l}\text { Highly expressed in } \\
\text { fibroblastic foci in IPF } \\
\text { patients }\end{array}$ & $(109,165)$ \\
\hline \multirow[t]{2}{*}{ Renal fibrosis } & $\begin{array}{c}\text { Enhances NLRP3 } \\
\text { inflammasome activation } \\
\text { and facilitates IL-23/IL-17 } \\
\text { signaling }\end{array}$ & N/A & $\mathrm{N} / \mathrm{A}$ & $\mathrm{N} / \mathrm{A}$ & $\begin{array}{l}\text { Attenuates renal } \\
\text { tubulointerstitial lesions }\end{array}$ & $(6,127)$ \\
\hline & $\begin{array}{l}\text { IL- } 36 \alpha^{+} \text {tubules correlated } \\
\text { with proteinuria, fibrosis } \\
\text { score, and the presence of } \\
\text { tubulointerstitial lesions }\end{array}$ & & & & & \\
\hline Myocardial fibrosis & $\mathrm{N} / \mathrm{A}$ & $\mathrm{N} / \mathrm{A}$ & $\mathrm{N} / \mathrm{A}$ & $\mathrm{N} / \mathrm{A}$ & $\begin{array}{c}\text { Reduces fibrotic area in } \\
\text { the heart }\end{array}$ & $(166)$ \\
\hline \multirow[t]{2}{*}{ Intestinal fibrosis } & $\begin{array}{l}\text { Increases intestinal } \\
\alpha-\mathrm{SMA}^{+} \text {cells in vivo }\end{array}$ & $\begin{array}{l}\text { Increases intestinal } \\
\alpha-S M A^{+} \text {cells in vivo }\end{array}$ & $\begin{array}{l}\text { Increases intestinal } \\
\alpha-S M A^{+} \text {cells in vivo }\end{array}$ & $\mathrm{N} / \mathrm{A}$ & $\mathrm{N} / \mathrm{A}$ & (7) \\
\hline & $\begin{array}{l}\text { Increases COL-VI } \\
\text { expression in colonic } \\
\text { fibroblasts }\end{array}$ & $\begin{array}{l}\text { Increases COL-VI } \\
\text { expression in colonic } \\
\text { fibroblasts }\end{array}$ & $\begin{array}{l}\text { Increases COL-VI } \\
\text { expression in colonic } \\
\text { fibroblasts }\end{array}$ & & & \\
\hline
\end{tabular}

${ }^{A} \mathrm{~N} / \mathrm{A}$ indicates not yet reported.

$40 \%$ of the population (85). As in other inflammatory and autoimmune diseases, Th17 cells have been implicated in AR. A recent study on regulation of Th17 cytokines by IL-36 found elevated mRNA and protein expression of all IL-36 agonists and IL-36R in AR patient serum; however, in AR mice only IL-36 $\alpha$ promoted differentiation and function of Th17 cells, and anti-IL-36 $\alpha$ treatment significantly alleviated the Th17 response (86). The authors also reported that stimulating eosinophils isolated from atopic donors with IL-36 $\gamma$ induced eosinophilic activation, a main characteristic of AR, as signified by promoting the adhesion, migration, and activation of eosinophils. These effects were inhibited by U0126 (a selective inhibitor of MEK1 and MEK2) and SB203580 (a selective inhibitor of p38 MAPK), suggesting the engagement of $\mathrm{p} 38$ MAPK and MEKs in the regulation of eosinophils (87). Currently, there are no active clinical trials focusing on IL-36 cytokines as therapeutic target for AR treatment.

\section{IL-36 in fibrotic disorders}

Fibrosis is defined by the excessive deposition of extracellular matrix (ECM) proteins resulting in the formation of scar tissue and loss of organ function. The major cell types associated with fibrosis are mesenchymal cells, such as fibroblasts and myofibroblasts. Upon stimulation by products of activated immune and nonimmune cells as well as pathogen-associated molecular patterns (PAMPs), these cells secrete a variety of ECM proteins such as collagen, fibronectin, and multiple others (88). Although acute injury usually only induces a transient fibrotic response, repeated injury, primarily of an inflammatory nature, can lead to a chronic fibrogenic response that can eventually progress independently of inflammation (89). While the role of IL-36 in acute and chronic inflammation is well established, less is known about its role in fibrotic disorders (Table 5).
Renal fibrosis. Renal fibrosis is characterized by the excessive accumulation of ECM, causing tubulointerstitial lesions (TILs) and glomerulosclerosis. In humans, IL-36 $\alpha$ is the most upregulated isoform in renal fibrosis, and its receptor complex IL-36R/IL-1RAcP has been demonstrated to be highly expressed in renal epithelial cells (6, $90,91)$. Overexpression of IL-36 $\alpha$ is highly correlated with the extent of renal fibrosis and the degree of mononuclear leukocyte infiltration in human urine and renal tissue, respectively (6).

In mice, the IL-36R/IL-1RAcP complex and all isoforms of IL-36 are expressed in renal tubular and glomerular epithelial tissue $(6,91$, $92)$, with IL-36 $\alpha$ again being the isoform with the highest expression $(6,91,92)$. Murine models of unilateral ureteral obstruction (UUO) exhibited IL-36 $\alpha$ overexpression, which correlated with increased $\alpha$-SMA ${ }^{+}$myofibroblasts on kidney histopathology (90). IL-36 $\alpha$ has functional relevance in kidney fibrosis, as shown in IL-36R ${ }^{-/-}(6)$ and IL-36 $\alpha^{-/-}(90)$ mice, in which renal cell death, TILs, IL-6, collagen type IV (COL-IV), and the collagen remodeling-associated enzyme PRSS35 were reduced compared with WT mice (90). IL-36R $\mathrm{R}^{-/-}$mice showed significantly reduced IL-23 and IL-17 mRNA expression, indicating that IL-36 signaling facilitates the induction of IL-23 and IL-17 (6). Further investigation demonstrated that IL-23-/- UUO murine models exhibited less macrophage infiltration and COL-IV deposition, and IL-36R knockout prevented TILs, attenuating renal inflammation and fibrosis (6). These findings suggest that IL-36 signaling facilitates macrophage infiltration and COL-IV deposition via the IL-23/IL-17 axis in renal fibrosis (6). The induction of IL-36 $\alpha$ and its signaling has also been explored in renal fibrosis. Lipopolysaccharide (LPS), a Toll-like receptor 4 (TLR4) ligand, induced IL-36 $\alpha$ production in a tubule epithelial cell (TEC) line (90), and TEC cultures demonstrated increased NF- $\mathrm{KB}$ activity and Erk phosphorylation (92), which suggests the activation of NF-KB and MAPK pathways might be critical 
for IL-36 $\alpha$ induction in the kidney (93-95). IL-36 $\alpha$ is a potent activator of the NLRP3 inflammasome, followed by subsequent activation of pro-IL-18/IL-1 $\beta$ signaling, as shown in vitro in mouse renal TECs, macrophages, and bone marrow-derived DCs as well as in vivo in a UUO model $(6,96)$.

In summary, IL-36R signaling could serve as a potential therapeutic target and biomarkers for early onset of chronic kidney disease (90-92). IL-36 $\alpha$ is the predominant isoform in kidney fibrosis and can be upregulated by LPS and mediates IL-17, IL-23, and NLRP3 signaling. Currently, there are no IL-36-modulating agents in clinical trials for the treatment of renal fibrosis.

Pulmonary fibrosis. Idiopathic pulmonary fibrosis (IPF) is a clinicopathologic entity characterized by dysregulation of alveolar epithelial cells and immune cell infiltrates resulting in pulmonary dysfunction $(97,98)$. The cellular expression of IL-36 has been explored in lung disorders. Bronchial epithelial cells (99), lung fibroblasts (99), eosinophils (87), and macrophages (100) express the IL-36R/IL-1RAcP complex and, in turn, have been demonstrated to respond to IL-36 cytokines $(99,101)$. Although all agonists of IL-36 have been shown to activate lung fibroblasts (101), human lung fibroblasts exposed to IL-36 $\gamma$ specifically increase expression of the inflammatory cytokines/ chemokines CCL2, CXCL10, G-CSF, GM-CSF, and IL-6, and the neutrophil chemokines IL-8/CXCL3 and CCL20 $(5,99)$ via the activation of MAPKs and transcription factors NF- $\mathrm{KB}$ and CREB. This has implications for the pathogenesis of fibrosis, since neutrophils are a known profibrotic cell type in various fibrotic disorders $(102,103)$ including IPF (104), and numerous studies have demonstrated that IL-36 $\alpha,-\beta$, and $-\gamma$ are indeed associated with pulmonary neutrophil accumulation (105-108) and collagen deposition (109). Additionally, neutrophilderived elastase, a major enzymatic activator of IL-36 $(110,111)$, plays critical roles in the pathogenesis of IPF $(112,113)$, likely by further activation of latent IL-36, leading to a forward-feeding loop of neutrophil recruitment and elastase secretion.

Macrophages (114), fibroblasts (115), and eosinophils (116) are potent producers of the profibrotic cytokine TGF- $\beta$, which initiates the differentiation of fibroblasts into myofibroblasts, induces epithelial-mesenchymal transition (EMT), and activates resident fibroblasts $(117,118)$, leading to the overexpression of ECM proteins (116) (Figure 1). IL-36 $\beta$ and $-\gamma$ have been demonstrated to activate eosinophils (87), fibroblasts, and macrophages (100). This implicates IL-36 as a link between cellular inflammation and progression to fibrosis and provides a potential feedback loop of IL-36-stimulated cells producing fibronectin and TGF- $\beta$, resulting in neutrophil chemotaxis and increasing their secretion of TGF- $\beta$ (Figure 1 ).

Altogether, the data suggest that IL-36, possibly with a predominance of IL-36 $\beta$ and $-\gamma$, facilitates pulmonary fibrosis by regulating immune cell recruitment and activation, resulting in further activation and differentiation of fibroblasts into myofibroblasts and excess ECM deposition. Neutrophil elastase in IPF may enhance IL-36 activity through its cleavage. There are currently no ongoing clinical trials examining IL-36 as a target in IPF.

Intestinal fibrosis. Intestinal fibrosis is a common complication of IBD that leads to narrowing of the lumen and eventually bowel obstruction (119). Although more evident in small bowel CD, fibrosis also occurs in colonic CD as well as in UC (120-123).

The expression of all IL-36 isoforms and the IL-36R/IL-1RAcP complex is increased in $\operatorname{IBD}(7,22,76,77)$. Recently, tissues from fibro- stenotic CD patients were found to have significantly higher levels of IL-36 $\alpha$, but not IL-36 $\beta$ or $-\gamma$, which correlated with a high number of activated $\alpha-\mathrm{SMA}^{+}$myofibroblasts (7). Intestinal IL-36 production has been demonstrated in human intestinal fibroblasts, myofibroblasts, epithelial cells, and tissue-resident macrophages $\left(\mathrm{CD} 14^{+} \mathrm{C}\right.$ D $\left.64^{+} \mathrm{CD} 163^{+}\right)(7,22,76,77)$, with macrophages believed to be its major source in strictures (7). Primary human colonic subepithelial myofibroblasts have been demonstrated to spontaneously produce IL-36 $\gamma$, displaying significant increases in IL-36 $\gamma$ when cells were cultured with IL-1 $\beta$ (21). RNA sequencing of IL-36R-stimulated human intestinal fibroblasts followed by gene ontology enrichment studies showed that IL-36R-stimulated fibroblasts upregulated biological processes related to fibrosis, such as inflammatory response, regulation of proliferation, and IL-6 production (7).

Functionally, anti-IL-36R antibody treatment attenuated fibrosis in chronic TNBS-induced murine colitis, and IL-36 $\mathrm{R}^{-/-}$mice portrayed significantly less fibrosis compared with WT mice in both chronic TNBS- and DSS-induced colitis models (7), providing strong evidence that IL-36R signaling plays an important role in intestinal fibrosis. Interestingly, similar to observations of the blockade of TNF $(124,125)$, IL-36R signaling exhibited opposing effects on the regulation of acute compared with chronic colonic inflammation $(7,126)$. These opposing effects may be attributed to the mechanistic changes in inflammation in early compared with late disease (126). The effects of IL-36R signaling attenuate acute inflammation but may drive fibrosis in chronic inflammation. Inflammation in chronic colitis may be propelled by the changes in responding fibroblasts, which become activated and produce profibrotic/inflammatory cytokines and chemokines (126). Of note, IL-36 ligands selectively upregulated COL-VI in murine colonic fibroblasts, and COL-VI is increased in the mucosa and submucosa of CD and UC patients (7). COL-I and COL-III are the major collagens reported to be elevated in intestinal strictures (120), and IL-36 may lead to a distinct regulation of collagen expression $(7,126)$.

Hence, while all IL-36 isoforms are upregulated in intestinal fibrosis, IL-36 $\alpha$, like in kidney fibrosis, appears to be the crucial factor activating IL-36R. Neutralizing antibodies targeting IL-36R are currently undergoing phase II clinical trials for the treatment of UC and CD (NCT03752970, NCT03123120, and NCT03482635), and a trial specifically targeting stricturing CD is in the planning stages.

\section{Conclusions and future directions}

Like other IL-1 family members, IL-36 agonists act primarily as molecules that promote the transcription of multiple inflammatory genes, justifying the investigation of their role in inflammation and inflammation-driven fibrosis. Under homeostatic conditions IL-36 is expressed in multiple cells, tissues, and organs and contributes to immune regulation but, if overproduced, it plays a pathogenic role in various chronic inflammatory and fibrotic disorders, as mentioned above. The action of IL-36 thus appears to be context dependent. It can be induced by classical proinflammatory cytokines as well as bacterial components, which - combined with the expression at mucosal surfaces and data from experimental models - appears to have the capability to restore epithelial integrity in acute inflammation with a net antiinflammatory role, possibly mediated by factors such as IL-22.

Strikingly, however, in chronic inflammation and tissue damage, IL-36 signaling through IL-36R can exert proinflammatory and in par- 
ticular profibrotic actions. It can be speculated that this switch in function is related to several factors. The immunophenotype in inflammatory disorders changes in late or chronic disease compared with early or self-limiting inflammation, and hence the milieu encountered in the tissues experiencing the action of IL-36 is quite different. More importantly, while IL-36 is elevated in acute and chronic inflammation, the cellular substrate it encounters is distinct. In chronic disease, an abundance of mesenchymal cells is present, expressing IL-36R and responding to IL-36 with a profibrotic program, with the subsequent release of ECM components into the surrounding tissue microenvironment. Furthermore, immune and nonimmune cell types that release profibrotic factors upon exposure to IL-36, such as TGF- $\beta 1$, indirectly drive fibrogenesis. Unexpected contributors to the pool of mesenchymal cells can be encountered, such as epithelial cells that in response to IL-36 acquire a mesenchymal cell phenotype - the process termed EMT. Finally, the IL-36 isoforms present in acute versus chronic inflammation or fibrotic disorders may vary, as indicated, for example, by a strong expression of IL-36 $\alpha$ in kidney and intestinal fibrosis. Given the high expression of IL-36 in chronic inflammation, several positive feedback loops of IL-36 promoting its own expression and activation followed by subsequent orchestration of profibrotic signaling cascades may make IL-36 a critical link responsible for the switch from inflammation to fibrosis.

What are future needs of investigation in this area? Within a given model system, such as IBD or other, a thorough mapping of the expression of IL-36 isoforms over time is warranted. It is reasonable to speculate that certain isoforms are predominantly present in different stages of disease. This has implications for future isotype-selective inhibition of IL-36. Most of the studies recapitulated in this review implicate IL-36 $\alpha$ and $-\gamma$ as the main contributors to disease pathogenesis. Herein, IL-36 $\beta$ has only been implicated as a pathogenic cytokine in arthritis (69) and future research should be devoted to elucidating its specific function. Noncanonical signaling pathways of IL-36 isoforms should be explored, as this would open additional targetable mechanism of antiinflammatory or antifibrotic therapies. Although the knowledge of the role of IL-36 in chronic inflammation has been used to understand its role in fibrogenesis, the reverse of this - understanding chronic inflammation from knowledge of IL-36 function in fibrosis - is lacking. These studies could include further understanding of the function of IL-36 in nonimmune cells, such as fibroblasts and smooth muscle cells, in inflammation rather than fibrosis, a still largely understudied area. In addition, elucidating the function of the ECM molecules induced by IL-36, in particular COL-VI, should be a research priority, as the ECM environment may be an active participant in tissue inflammation. Ultimately, most studies of IL-36 biology are still restricted to pure expression studies in human tissues complemented by animal models, but studies in primary human cells or even better, primary human cell-cell interaction models in vitro may shed further insight into its mechanism. Finally, IL-36 may be employed as a biomarker of disease severity, a predictor of more severe disease courses, or a response to anti-IL-36-directed therapies, and future prospective studies are needed to dissect this notion.

Based on this fairly solid evidence, considering IL-36 as a therapeutic target in inflammatory and fibrotic conditions appears well justified. Targeting could be accomplished in multiple ways, such as using neutralizing antibodies against all IL-36 isoforms combined or individual isoforms, inhibiting posttranslational IL-36 processing, administering IL-36Ra or IL-38, and targeting IL-1RAcP $(111,127)$. Clinical trials have started in a few diseases with a presumed critical role of IL-36 such as pustular psoriasis and IBD, with the results still pending. Many more disorders discussed in this review provide a biological rationale for future clinical trials. Although knowledge of IL-36 is incomplete and still growing, its dual role in inflammation and fibrosis makes it unique among a myriad of other cytokines (26) and bolsters the notion that this particular IL-1 family member is indeed a crucial link between inflammation and fibrosis.

Address correspondence to: Florian Rieder, Department of Inflammation and Immunity, and Department of Gastroenterology, Hepatology \& Nutrition, The Cleveland Clinic Foundation, 9500 Euclid Avenue, Cleveland, Ohio 44195, USA. Phone: 216.445.4916; E-mail: riederf@ccf.org.
1. Sims JE, et al. cDNA expression cloning of the IL-1 receptor, a member of the immunoglobulin superfamily. Science. 1988;241(4865):585-589.

2. Buhl AL, Wenzel J. Interleukin-36 in infectious and inflammatory skin diseases. Front Immunol. 2019;10:1162.

3. Yuan Z-C, et al. Biology of IL-36 signaling and its role in systemic inflammatory diseases. Front Immunol. 2019;10:2532.

4. Artlett CM. The IL-1 family of cytokines. Do they have a role in scleroderma fibrosis? Immunol Lett. 2018;195:30-37.

5. Borthwick LA. The IL-1 cytokine family and its role in inflammation and fibrosis in the lung. Semin Immunopathol. 2016;38(4):517-534.

6. Chi HH, et al. IL-36 signaling facilitates activation of the NLRP3 inflammasome and IL-23/ IL-17 axis in renal inflammation and fibrosis. JAm Soc Nephrol. 2017;28(7):2022-2037.

7. Scheibe $\mathrm{K}$, et al. Inhibiting interleukin 36 receptor signaling reduces fibrosis in mice with chronic intestinal inflammation. Gastroenterology. 2019;156(4):1082-1097.e11.
8. Nishida A, et al. Interleukin-36 $\alpha$ induces inflammatory mediators from human pancreatic myofibroblasts via a MyD88 dependent pathway. Pancreas. 2017;46(4):539-548.

9. Sims JE, et al. A new nomenclature for IL-1-family genes. Trends Immunol. 2001;22(10):536-537.

10. Murrieta-Coxca JM, et al. IL-36 cytokines: regulators of inflammatory responses and their emerging role in immunology of reproduction. Int J Mol Sci. 2019;20(7):1649.

11. Harusato A, et al. IL-36 $\gamma$ signaling controls the induced regulatory $\mathrm{T}$ cell-Th9 cell balance via NFкB activation and STAT transcription factors. Mucosal Immunol. 2017;10(6):1455-1467.

12. Towne JE, et al. Interleukin (IL)-1F6, IL-1F8, and IL-1F9 signal through IL-1Rrp2 and IL-1RAcP to activate the pathway leading to NF-kappaB and MAPKs. J Biol Chem. 2004;279(14):13677-13688.

13. Yi G, et al. Structural and functional attributes of the interleukin-36 receptor. J Biol Chem. 2016;291(32):16597-16609.

14. Towne JE, Sims JE. IL-36 in psoriasis. Curr Opin Pharmacol. 2012;12(4):486-490.
15. Dinarello CA. The IL-1 family of cytokines and receptors in rheumatic diseases. Nat Rev Rheumatol. 2019;15(10):612-632.

16. Akdis $\mathrm{M}$, et al. Interleukins (from IL-1 to IL-38), interferons, transforming growth factor $\beta$, and TNF- $\alpha$ : Receptors, functions, and roles in diseases. J Allergy Clin Immunol. 2016;138(4):984-1010.

17. Foster AM, et al. IL-36 promotes myeloid cell infiltration, activation, and inflammatory activity in skin. J Immunol. 2014;192(12):6053-6061.

18. Hernandez-Santana YE, et al. Keratinocyte interleukin-36 receptor expression orchestrates psoriasiform inflammation in mice. Life Sci Alliance. 2020;3(4):e201900586.

19. Catapano M, et al. IL-36 Promotes systemic IFN-I responses in severe forms of psoriasis. JInvest Dermatol. 2020;140(4):816-826.e3.

20. Zhou L, Todorovic V. Interleukin-36: structure, signaling and function [published online February 6, 2020]. Adv ExpMed Biol. https:// doi: 10.1007/5584_2020_488.

21. Takahashi $\mathrm{K}$, et al. Interleukin (IL)-1 $\beta$ is a strong inducer of IL-36 $\gamma$ expression in human colonic 
myofibroblasts. PLoS One. 2015;10(11):e0138423.

22. Scheibe K, et al. IL-36R signalling activates intestinal epithelial cells and fibroblasts and promotes mucosal healing in vivo. Gut. 2017;66(5):823-838.

23. Towne JE, et al. Interleukin-36 (IL-36) ligands require processing for full agonist (IL-36alpha, IL-36beta, and IL-36gamma) or antagonist (IL-36Ra) activity. J Biol Chem. 2011;286(49):42594-602.

24. Wissbrock A, et al. Structural insights into heme binding to IL-36 $\alpha$ proinflammatory cytokine. Sci Rep. 2019;9(1):16893.

25. Milora KA, et al. Unprocessed interleukin-36 $\alpha$ regulates psoriasis-like skin inflammation in cooperation with interleukin-1. J Invest Dermatol. 2015;135(12):2992-3000.

26. Mantovani A, et al. Interleukin-1 and related cytokines in the regulation of inflammation and immunity. Immunity. 2019;50(4):778-795.

27. Smith DE, et al. Four new members expand the interleukin-1 superfamily. J Biol Chem. 2000;275(2):1169-1175.

28. Mulero JJ, et al. IL1HY1: a novel interleukin-1 receptor antagonist gene. Biochem Biophys Res Commun. 1999;263(3):702-706.

29. Wang $\mathrm{H}$, et al. The activation and function of IL-36 $\gamma$ in neutrophilic inflammation in chronic rhinosinusitis. JAllergy Clin Immunol. 2018;141(5):1646-1658.

30. Kim SJ, et al. Increased cathepsin S in Prdm1 ${ }^{-}$ dendritic cells alters the $\mathrm{T}_{\mathrm{FH}}$ cell repertoire and contributes to lupus. Nat Immunol. 2017;18(9):1016-1024.

31. Ainscough JS, et al. Cathepsin S is the major activator of the psoriasis-associated proinflammatory cytokine IL-36 $\gamma$. Proc Natl Acad Sci U S A. 2017;114(13):E2748-E2757.

32. Lian LH, et al. The double-stranded RNA analogue polyinosinic-polycytidylic acid induces keratinocyte pyroptosis and release of IL-36 $\gamma$. J Invest Dermatol. 2012;132(5):1346-1353.

33. Macleod T, et al. Neutrophil elastase-mediated proteolysis activates the anti-inflammatory cytokine IL-36 receptor antagonist. Sci Rep. 2016;6:24880

34. Zhou L, et al. Quantitative ligand and receptor binding studies reveal the mechanism of interleukin-36 (IL-36) pathway activation. J Biol Chem. 2018;293(2):403-411.

35. Gunther S, Sundberg EJ. Molecular determinants of agonist and antagonist signaling through the IL-36 receptor. J Immunol. 2014;193(2):921-930.

36. van de Veerdonk FL, et al. IL-38 binds to the IL-36 receptor and has biological effects on immune cells similar to IL-36 receptor antagonist. Proc Natl Acad Sci U S A. 2012;109(8):3001-3005.

37. Liu H, et al. Staphylococcus aureus epicutaneous exposure drives skin inflammation via IL-36mediated $\mathrm{T}$ cell responses. Cell Host Microbe. 2017;22(5):653-666.e5.

38. Kanda T, et al. Interleukin(IL)-36 $\alpha$ and IL-36 $\gamma$ induce proinflammatory mediators from human colonic subepithelial myofibroblasts. Front Med (Lausanne). 2015;2:69.

39. Swindell WR, et al. RNA-seq analysis of IL-1B and IL-36 responses in epidermal keratinocytes identifies a shared MyD88-dependent gene signature. Front Immunol. 2018;9:80.

40. Lin SC, et al. Helical assembly in the MyD88IRAK4-IRAK2 complex in TLR/IL-1R signalling. Nature. 2010;465(7300):885-890.

41. Wang L, et al. Crystal structure of human IRAK1. Proc Natl Acad Sci U S A. 2017;114(51):13507-13512.

42. Verstak B, et al. MyD88 adapter-like (Mal)/ TIRAP interaction with TRAF6 is critical for TLR2- and TLR4-mediated NF-kappaB proinflammatory responses. J Biol Chem. 2009;284(36):24192-24203.

43. Carrier Y, et al. Inter-regulation of Th17 cytokines and the IL-36 cytokines in vitro and in vivo: implications in psoriasis pathogenesis. J Invest Dermatol. 2011;131(12):2428-2437.

44. Müller A, et al. IкB $\zeta$ is a key transcriptional regulator of IL-36-driven psoriasis-related gene expression in keratinocytes. Proc Natl Acad Sci U S A. 2018;115(40):10088-10093.

45. Müller A, et al. The CDK4/6-EZH2 pathway is a potential therapeutic target for psoriasis. JClin Invest. 2020;130(11):5765-5781.

46. Gao Y, et al. IL-36 $\gamma$ promotes killing of Mycobacterium tuberculosis by macrophages via WNT5A-Induced noncanonical WNT signaling. JImmunol. 2019;203(4):922-935.

47. Wang W, et al. IL-36 $\gamma$ inhibits differentiation and induces inflammation of keratinocyte via Wnt signaling pathway in psoriasis. Int JMed Sci. 2017;14(10):1002-1007.

48. Boehncke WH, Schön MP. Psoriasis. Lancet. 2015;386(9997):983-994.

49. Blumberg $\mathrm{H}$, et al. Opposing activities of two novel members of the IL- 1 ligand family regulate skin inflammation. JExp Med. 2007;204(11):2603-2614.

50. Johnston A, et al. IL-1F5, -F6, -F8, and -F9: a novel IL-1 family signaling system that is active in psoriasis and promotes keratinocyte antimicrobial peptide expression. JImmunol. 2011;186(4):2613-2622.

51. Sommerfeld SD, et al. Interleukin-36y-producing macrophages drive IL-17-mediated fibrosis. Sci Immunol. 2019;4(40):eaax4783.

52. Bridgewood C, et al. IL-36gamma is a strong inducer of IL-23 in psoriatic cells and activates angiogenesis. Front Immunol. 2018;9:200.

53. Tortola $\mathrm{L}$, et al. Psoriasiform dermatitis is driven by IL-36-mediated DC-keratinocyte crosstalk. JClin Invest. 2012;122(11):3965-3976.

54. Sano S, et al. Stat3 links activated keratinocytes and immunocytes required for development of psoriasis in a novel transgenic mouse model. Nat Med. 2005;11(1):43-49.

55. Ohko K, et al. IL-36 signaling is a gatekeeper for both keratinocytes and dendritic cells linking innate immunity to psoriatic nature. J Dermatol Sci. 2016;84(1):e60.

56. Tusher VG, et al. Significance analysis of microarrays applied to the ionizing radiation response. Proc Natl Acad Sci U S A. 2001;98(9):5116-5121.

57. D'Erme AM, et al. IL-36 $\gamma$ (IL-1F9) is a biomarker for psoriasis skin lesions. J Invest Dermatol. 2015;135(4):1025-1032.

58. Mercurio L, et al. IL-38 has an anti-inflammatory action in psoriasis and its expression correlates with disease severity and therapeutic response to anti-IL-17A treatment. Cell Death Dis. 2018;9(11):1104.

59. Ogawa E, et al. Pathogenesis of psoriasis and development of treatment. J Dermatol. 2018;45(3):264-272.

60. Todorovic V, et al. Small molecule IL-36 $\gamma$ antagonist as a novel therapeutic approach for plaque psoriasis. Sci Rep. 2019;9(1):9089.

61. Bachelez $\mathrm{H}$, et al. Inhibition of the interleukin-36 pathway for the treatment of generalized pustular psoriasis. NEnglJMed. 2019;380(10):981-983.

62. Merola JF, et al. Distinguishing rheumatoid arthritis from psoriatic arthritis. RMD Open. 2018;4(2):e000656.

63. Busse K, Liao W. Which psoriasis patients develop psoriatic arthritis? Psoriasis Forum. 2010;16(4):17-25.

64. Rahman P, et al. Association between the interleukin-1 family gene cluster and psoriatic arthritis. Arthritis Rheum. 2006;54(7):2321-2325.

65. Belasco J, et al. Comparative genomic profiling of synovium versus skin lesions in psoriatic arthritis. Arthritis Rheumatol. 2015;67(4):934-944.

66. Benham H, et al. Th17 and Th22 cells in psoriatic arthritis and psoriasis. Arthritis Res Ther. 2013;15(5):R136.

67. Raychaudhuri SK, et al. Role of IL-17 in the pathogenesis of psoriatic arthritis and axial spondyloarthritis. Clin Rheumatol. 2015;34(6):1019-1023.

68. Frey S, et al. The novel cytokine interleukin-36 $\alpha$ is expressed in psoriatic and rheumatoid arthritis synovium. Ann Rheum Dis. 2013;72(9):1569-1574.

69. Magne D, et al. The new IL-1 family member IL-1F8 stimulates production of inflammatory mediators by synovial fibroblasts and articular chondrocytes. Arthritis Res Ther. 2006;8(3):R80.

70. Gaffen SL. The role of interleukin-17 in the pathogenesis of rheumatoid arthritis. Curr Rheumatol Rep. 2009;11(5):365-370.

71. Derer A, et al. Blockade of IL-36 receptor signaling does not prevent from TNF-induced arthritis. PLoS One. 2014;9(8):e101954.

72. Li T, et al. TGF- $\beta$ type 2 receptor-mediated modulation of the IL-36 family can be therapeutically targeted in osteoarthritis. Sci Transl Med. 2019;11(491):eaan2585.

73. Boutet MA, et al. Interleukin-36 family dysregulation drives joint inflammation and therapy response in psoriatic arthritis. Rheumatology (Oxford). 2020;59(4):828-838.

74. Simone D, et al. Disease-modifying antirheumatic drugs (DMARD) and combination therapy of conventional DMARD in patients with spondyloarthritis and psoriatic arthritis with axial involvement. J Rheumatol Suppl. 2015;93:65-69.

75. Boutet MA, et al. Distinct expression of interleukin (IL)-36 $\alpha, \beta$ and $\gamma$, their antagonist IL-36Ra and IL-38 in psoriasis, rheumatoid arthritis and Crohn's disease. Clin Exp Immunol. 2016;184(2):159-173.

76. Russell SE, et al. IL-36 $\alpha$ expression is elevated in ulcerative colitis and promotes colonic inflammation. Mucosal Immunol. 2016;9(5):1193-1204.

77. Nishida A, et al. Increased expression of interleukin-36, a member of the interleukin-1 cytokine family, in inflammatory bowel disease. Inflamm Bowel Dis. 2016;22(2):303-314. 
78. Xie C, et al. Interleukin-38 is elevated in inflammatory bowel diseases and suppresses intestinal inflammation. Cytokine. 2020;127:154963.

79. Fonseca-Camarillo G, et al. Differential expression of IL-36 family members and IL-38 by immune and nonimmune cells in patients with active inflammatory bowel disease. Biomed Res Int. 2018;2018:5140691.

80. Medina-Contreras O, et al. Cutting edge: IL-36 receptor promotes resolution of intestinal damage. J Immunol. 2016;196(1):34-38.

81. Mizoguchi A. Healing of intestinal inflammation by IL-22. Inflamm Bowel Dis. 2012;18(9):1777-1784.

82. Ngo VL, et al. A cytokine network involving

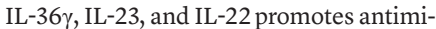
crobial defense and recovery from intestinal barrier damage. Proc Natl Acad Sci U S A. 2018;115(22):E5076-E5085

83. Sonnenberg GF, et al. Border patrol: regulation of immunity, inflammation and tissue homeostasis at barrier surfaces by IL-22. Nat Immunol. 2011;12(5):383-390.

84. Shih VF, et al. Homeostatic IL-23 receptor signaling limits Th17 response through IL-22-mediated containment of commensal microbiota. Proc Nat Acad Sci U S A. 2014;111(38):13942-13947.

85. Small P, et al. Allergic rhinitis. Allergy Asthma Clin Immunol. 2018;14(suppl 2):51.

86. Qin X, et al. IL-36 $\alpha$ contributes to enhanced T helper 17 type responses in allergic rhinitis. Cytokine. 2020;128:154992.

87. Qin X, et al. The role of IL-36 $\gamma$ and its regulation in eosinophilic inflammation in allergic rhinitis. Cytokine. 2019;117:84-90.

88. Kendall RT, Feghali-Bostwick CA. Fibroblasts in fibrosis: novel roles and mediators. Front Pharmacol. 2014;5:123.

89. Wynn TA. Cellular and molecular mechanisms of fibrosis. J Pathol. 2008;214(2):199-210.

90. Ichii O, et al. IL-36 $\alpha$ Regulates tubulointerstitial inflammation in the mouse kidney. Front Immunol. 2017;8:1346.

91. Ichii O, et al. Local overexpression of interleukin-1 family, member 6 relates to the develop ment of tubulointerstitial lesions. Lab Invest. 2010;90(3):459-475.

92. Nishikawa H, et al. Knockout of the interleukin-36 receptor protects against renal ischemia-reperfusion injury by reduction of proinflammatory cytokines. Kidney Int 2018;93(3):599-614.

93. Sen R, Baltimore D. Inducibility of kappa immunoglobulin enhancer-binding protein Nf-kappa B by a posttranslational mechanism. Cell. 1986;47(6):921-928.

94. Han J, et al. Endotoxin induces rapid protein tyrosine phosphorylation in 70Z/3 cells expressing CD14. J Biol Chem. 1993;268(33):25009-14.

95. O'Neill LA, et al. The history of Toll-like receptors - redefining innate immunity. Nat Rev Immunol. 2013;13(6):453-460.

96. Latz E, et al. Activation and regulation of the inflammasomes. Nat Rev Immunol. 2013;13(6):397-411.

97. King TE Jr., et al. Idiopathic pulmonary fibrosis. Lancet. 2011;378(9807):1949-1961.

98. Lynch JP, III, Belperio JA. Idiopathic pulmonary fibrosis. Diffuse Lung Disease. 2011:171-194.
99. Chustz RT, et al. Regulation and function of the IL-1 family cytokine IL-1F9 in human bronchial epithelial cells. Am J Respir Mol Biol. 2011;45(1):145-153.

100.Dietrich D, et al. Interleukin-36 potently stimulates human M2 macrophages, langerhans cells and keratinocytes to produce pro-inflammatory cytokines. Cytokine. 2016;84:88-98.

101.Zhang J, et al. IL-36 induces cytokine IL-6 and chemokine CXCL8 expression in human lung tissue cells: implications for pulmonary inflammatory responses. Cytokine. 2017;99:114-123.

102. Barnes TC, et al. Neutrophil-derived reactive oxygen species in SSc. Rheumatology. 2012;51(7):1166-1169.

103. Svegliati-Baroni $\mathrm{G}$, et al. Involvement of reactive oxygen species and nitric oxide radicals in activation and proliferation of rat hepatic stellate cells. Liver. 2001;21(1):1-12.

104.Wynn TA. Integrating mechanisms of pulmonary fibrosis. J Exp Med. 2011;208(7):1339-1350.

105. Ramadas RA, et al. IL-36 $\alpha$ exerts pro-inflammatory effects in the lungs of mice. PLoS One. 2012;7(9):e45784

106.Parsanejad R, et al. Distinct regulatory profiles of interleukins and chemokines in response to cigarette smoke condensate in normal human bronchial epithelial (NHBE) cells. J Interferon Cytokine Res. 2008;28(12):703-712.

107. Gabay C, Towne JE. Regulation and function of interleukin-36 cytokines in homeostasis and pathological conditions. J Leukoc Biol. 2015;97(4):645-652.

108. Ramadas RA, et al. Interleukin-1 family member 9 stimulates chemokine production and neutrophil influx in mouse lungs. Am J Respir Cell Mol Biol. 2011;44(2):134-145.

109. Sun Y, et al. 253 : IL-36 induces inflammation and collagen deposition in the lung. Cytokine. 2013;63(3):303. https://doi.org/10.1016/j. cyto.2013.06.256

110. Lefrançais E, et al. IL-33 is processed into mature bioactive forms by neutrophil elastase and cathepsin G. Proc Natl Acad Sci U S A. 2012;109(5):1673-1678.

111. Sullivan GP, et al. Suppressing IL-36-driven inflammation using peptide pseudosubstrates for neutrophil proteases. Cell Death Dis. 2018;9(3):378

112. Van Linthout S, et al. Crosstalk between fibroblasts and inflammatory cells. Cardiovasc Res. 2014;102(2):258-69.

113. Takemasa A, et al. A neutrophil elastase inhibitor prevents bleomycin-induced pulmonary fibrosis in mice. Eur Respir J. 2012;40(6):1475-1482.

114. Verrecchia F, Mauviel A. Transforming growth factor-beta and fibrosis. World J Gastroenterol. 2007;13(22):3056-3062.

115. Hanna A, Frangogiannis NG. The role of the TGF- $\beta$ superfamily in myocardial infarction. Front Cardiovasc Med. 2019;6:140.

116. Aceves SS, Ackerman SJ. Relationships between eosinophilic inflammation, tissue remodeling, and fibrosis in eosinophilic esophagitis. Immunol Allergy Clin North Am. 2009;29(1):197-211, xiii-xiv.

117. Brønnum H, et al. IL-1 $\beta$ suppresses TGF- $\beta$ mediated myofibroblast differentiation in cardiac fibroblasts. Growth Factors. 2013;31(3):81-89.
118. Meyer-Ter-Vehn T, et al. P38 inhibitors prevent TGF-beta-induced myofibroblast transdifferentiation in human tenon fibroblasts. Invest Ophthalmol Vis Sci. 2006;47(4):1500-1509.

119. Latella G, Rieder F. Intestinal fibrosis: ready to be reversed. Curr Opin Gastroenterol. 2017;33(4):239-245.

120. Rieder F, et al. Mechanisms, management, and treatment of fibrosis in patients with inflammatory bowel diseases. Gastroenterology. 2017;152(2):340-350.e6.

121. De Dombal FT, et al. Local complications of ulcerative colitis: stricture, pseudopolyposis and carcinoma of colon and rectum. Br Med J. 1966;1(5501):1442-1447.

122. Edwards FC, Truelove SC. The course and prognosis of ulcerative colitis. III. Complications. Gut. 1964;5(1):1-22.

123. Gumaste V, et al. Benign and malignant colorectal strictures in ulcerative colitis. Gut. 1992;33(7):938-941.

124. Kojouharoff G, et al. Neutralization of tumour necrosis factor (TNF) but not of IL-1 reduces inflammation in chronic dextran sulphate sodium-induced colitis in mice. Clin Exp Immunol. 1997;107(2):353-358.

125. Noti M, et al. TNF suppresses acute intestinal inflammation by inducing local glucocorticoid synthesis. J Exp Med. 2010;207(5):1057-1066.

126. Mao R, Rieder F. Cooling down the hot potato: anti-interleukin 36 therapy prevents and treats experimental intestinal fibrosis. Gastroenterology. 2019;156(4):871-873

127. Højen JF, et al. IL-1R3 blockade broadly attenuates the functions of six members of the IL-1 family, revealing their contribution to models of disease. Nat Immunol. 2019;20(9):1138-1149.

128. Aoyagi T, et al. Interleukin-36 $\gamma$ and IL-36 receptor signaling mediate impaired host immunity and lung injury in cytotoxic Pseudomonas aeruginosa pulmonary infection: role of prostaglandin E2. PLoS Pathog. 2017;13(11):e1006737.

129. Vigne $S$, et al. IL-36 signaling amplifies Th1 responses by enhancing proliferation and Th1 polarization of naive $\mathrm{CD}^{+}{ }^{+} \mathrm{T}$ cells. Blood. 2012;120(17):3478-3487.

130. Vigne S, et al. IL-36R ligands are potent regulators of dendritic and T cells. Blood. 2011;118(22):5813-5823.

131. Morales Del Valle C, et al. Costimulation induces CD4 $\mathrm{T}$ cell antitumor immunity via an innate-like mechanism. Cell Rep. 2019;27(5):1434-1445.e3.

132. Gresnigt MS, et al. The IL-36 receptor pathway regulates Aspergillus fumigatus-induced Th1 and Th17 responses. Eur JImmunol. 2013;43(2):416-426.

133. Zhao X, et al. IL-36 $\beta$ promotes $\mathrm{CD}^{+} \mathrm{T}$ cell activation and antitumor immune responses by activating mTORC1. Front Immunol. 2019;10:1803.

134. Chu M, et al. Elevated expression and proinflammatory activity of IL-36 in patients with systemic lupus erythematosus. Molecules. 2015;20(10):19588-19604.

135. Mutamba S, et al. Expression of IL-1Rrp2 by human myelomonocytic cells is unique to DCs and facilitates DC maturation by IL-1F8 and IL-1F9. Eur J Immunol. 2012;42(3):607-617.

136. Hashiguchi Y, et al. IL-36 $\alpha$ from skin-resident cells plays an important role in the pathogenesis 
of imiquimod-induced psoriasiform dermatitis by forming a local autoamplification loop. J Immunol. 2018;201(1):167-182.

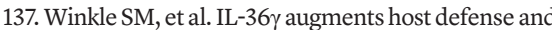
immune responses in human female reproductive tract epithelial cells. Front Microbiol. 2016;7:955.

138. Heath JE, et al. IL-36 $\gamma$ regulates mediators of tissue homeostasis in epithelial cells. Cytokine. 2019;119:24-31.

139. Bridgewood C, et al. IL-36 $\gamma$ has proinflammatory effects on human endothelial cells. Exp Dermatol. 2017;26(5):402-408.

140. Mercurio L, et al. Interleukin (IL)-17/IL-36 axis participates to the crosstalk between endothelial cells and keratinocytes during inflammatory skin responses. PLoS One. 2020;15(4):e0222969.

141. Schmitt V, et al. Interleukin-36 receptor mediates the crosstalk between plasma cells and synovial fibroblasts. Eur JImmunol. 2017;47(12):2101-2112.

142. Li Q, et al. Spinal IL-36 /IL-36R participates in the maintenance of chronic inflammatory pain through astroglial JNK pathway. Glia. 2019;67(3):438-451.

143. Li Y, et al. Interleukin-38 inhibits adipogenesis and inflammatory cytokine production in 3T3-L1 preadipocytes. Cell Biol Int. 2020;44(11):2357-2362.

144. Martin U, et al. Externalization of the leaderless cytokine IL-1F6 occurs in response to lipopolysaccharide/ATP activation of transduced bone marrow macrophages. J Immunol. 2009;183(6):4021-4030.

145. Shao $S$, et al. Neutrophil extracellular traps promote inflammatory responses in psoriasis via activating epidermal TLR4/IL-36R crosstalk. Front Immunol. 2019;10:746.

146. Boutet MA, et al. IL-36, IL-37, and IL-38 cytokines in skin and joint inflammation: a comprehensive review of their therapeutic potential. Int J Mol Sci. 2019;20(6):1257.

147. Madonna S, et al. The significance of IL-36 hyperactivation and IL-36R targeting in psoriasis. Int J Mol Sci. 2019;20(13):E3318.

148. Liu XG, et al. Interleukin-36 receptor antagonist alleviates airway inflammation in asthma via inhibiting the activation of interleukin-36 pathway. Int Immunopharmacol. 2020;81:106200.

149. Berglöf E, et al. IL-1Rrp2 expression and IL-1F9 (IL-1H1) actions in brain cells. J Neuroimmunol. 2003;139(1-2):36-43.

150. Aoyagi T, et al. IL-36 receptor deletion attenuates lung injury and decreases mortality in murine influenza pneumonia. Mucosal Immunol. 2017;10(4):1043-1055.

151. Wang X, et al. IL-36 $\gamma$ Transforms the tumor microenvironment and promotes type 1 lymphocyte-mediated antitumor immune responses. Cancer Cell. 2015;28(3):296-306.

152. Chen F, et al. IL-36 s in the colorectal cancer: is interleukin 36 good or bad for the development of colorectal cancer? BMC Cancer. 2020;20(1):92.

153. Queen D, et al. Function and regulation of IL-36 signaling in inflammatory diseases and cancer development. Front Cell Dev Biol. 2019;7:317.

154. Murrieta-Coxca JM, et al. Estrous cycle and gestational age-dependent expression of members of the interleukin- 36 subfamily in a semi-allogeneic model of infected and non-infected murine pregnancy. Front Immunol. 2016;7:376.

155. Ohko K, et al. IL-36 signaling is essential for psoriatic inflammation through the augmentation of innate immune responses. JInvest Dermatol. 2019;139(6):1400-1404.

156. Han Y, et al. IL-38 ameliorates skin inflammation and limits IL-17 production from $\gamma \delta \mathrm{T}$ cells. Cell
Rep. 2019;27(3):835-846.e5.

157. Henry CM, et al. Neutrophil-derived proteases escalate inflammation through activation of IL-36 family cytokines. Cell Rep. 2016;14(4):708-722.

158. Farooq M, et al. Mutation analysis of the IL36RN gene in 14 Japanese patients with generalized pustular psoriasis. Hum Mutat. 2013;34(1):176-183.

159. Onoufriadis A, et al. Mutations in IL36RN/IL1F5 are associated with the severe episodic inflammatory skin disease known as generalized pustular psoriasis. Am J Hum Genet. 2011;89(3):432-437.

160. Marrakchi S, et al. Interleukin-36-receptor antagonist deficiency and generalized pustular psoriasis. N Engl J Med. 2011;365(7):620-628.

161. Blumberg H, et al. IL-1RL2 and its ligands contribute to the cytokine network in psoriasis. J Immunol. 2010;185(7):4354-4362.

162. Mai SZ, et al. Increased serum IL-36 $\alpha$ and IL-36 $\gamma$ levels in patients with systemic lupus erythematosus: association with disease activity and arthritis. Int Immunopharmacol. 2018;58:103-108.

163. Li Y, et al. Adaptive immune response in osteoclastic bone resorption induced by orally administered Aggregatibacter actinomycetemcomitans in a rat model of periodontal disease. Mol Oral Microbiol. 2010;25(4):275-292.

164. Friedrich M, et al. IL-36 $\gamma$ sustains a proinflammatory self-amplifying loop with IL-17C in anti-TNF-induced psoriasiform skin lesions of patients with Crohn's disease. Inflamm Bowel Dis. 2014;20(11):1891-1901.

165. Tominaga M, et al. Overexpression of IL-38 protein in anticancer drug-induced lung injury and acute exacerbation of idiopathic pulmonary fibrosis. Respir Investig. 2017;55(5):293-299.

166. Wei Y, et al. Interleukin-38 alleviates cardiac remodelling after myocardial infarction. J Cell Mol Med. 2020;24(1):371-384. 